\title{
FORUM
}

Submitted 07.10.2019. Approved 09.04.2019

Evaluated through a double-blind review process. Guest Scientific Editors: Delane Botelho and Leandro Angotti Guissoni

Original version

DOI: http://dx.doi.org/10.1590/So034-759020200103

\section{DISHONESTY IS CONTAGIOUS: INVESTIGATING THE DOMINO EFFECT OF DYSFUNCTIONAL CUSTOMER BEHAVIORS}

\author{
Desonestidade é contagiosa: Investigando o efeito dominó do comportamento \\ disfuncional do consumidor
}

\author{
La Deshonestidad es contagiosa: El efecto dominó del comportamiento disfuncional \\ del consumidor
}

\begin{abstract}
The interaction between dysfunctional customers and other customers can cause the domino effect (i.e., the dissemination of a dysfunctional client's behavior to other nearby clients). However, it is not understood if this effect will manifest under certain levels of damage to the company. This study thus aims to verify if the amount of damage from the dysfunctional behavior can affect the probability of the domino effect. Through five experimental studies, we prove that the amount of damage influences the likelihood of dysfunctional behavior replication. Moreover, we found that this effect is explained by the acceptability of the dysfunctional behavior. We also identify that a consumer's ethics level, perception of risk in replicating the behavior, and social distance acts as boundary conditions of the amount of damage effect on the probability of replicating the dysfunctional behavior.
\end{abstract}

KEYWORDS | Dysfunctional behavior, domino effect, ethics, perception of risk, contagious effect.

\section{LÉLIS BALESTRIN ESPARTEL ${ }^{1}$ lbespartel@pucrs.br ORCID: 0000-0003-1062-9817}

\section{CLECIO FALCAO ARAUJO ${ }^{12}$}

clecioa@bol.com.br

ORCID: 0000-0002-8753-5184

\section{KENNY BASSO 3}

bassokenny@gmail.com

ORCID: 0000-0003-2853-0903

1Pontifícia Universidade Católica do Rio Grande do Sul, Escola de Negócios, Porto Alegre, RS, Brazil

2Universidade Regional do Noroeste do Estado do Rio Grande do Sul, Programa de Pós-Graduação em Desenvolvimento Regional, ljuí, RS, Brazil

${ }^{3}$ Cooperando Inteligência + Interação \& B-LAB Learning Space, Passo Fundo, RS, Brazil

\section{RESUMO}

A interação entre clientes disfuncionais e outros clientes pode causar o efeito dominó (ou seja, a disseminação do comportamento de um cliente disfuncional para outros clientes próximos). No entanto, não há uma compreensão se esse efeito ocorrerá em tamanhos diferentes de danos à empresa. Nesse sentido, esta pesquisa tem como objetivo verificar se o tamanho do dano pode afetar a ocorrência de efeito dominó do comportamento disfuncional. Através de cinco estudos experimentais, verificamos que o tamanho do dano influencia a probabilidade de replicar um comportamento disfuncional. Além disso, descobrimos que esse efeito é explicado pela aceitabilidade de um comportamento disfuncional. Também identificamos que o nível de ética do consumidor, a percepção de risco ao replicar o comportamento e a distância social atuam como condicionantes do efeito do tamanho do dano na probabilidade de replicar o comportamento disfuncional.

PALAVRAS-CHAVE / Comportamento disfuncional, efeito dominó, ética, percepção de risco, efeito de contágio.

\section{RESUMEN}

La interacción entre clientes disfuncionales y otros clientes puede causar un efecto dominó (es decir, la diseminación del comportamiento de un cliente disfuncional entre otros clientes cercanos). No obstante, no se entiende si este efecto se manifestará en diferentes proporciones de daño a la empresa. Por lo tanto, este estudio tiene como objetivo verificar si la proporción del daño del comportamiento disfuncional puede afectar la probabilidad del efecto dominó. A través de cinco estudios experimentales, verificamos que la proporción del daño influye en la probabilidad de replicación del comportamiento disfuncional. Además, descubrimos que ese efecto se explica por la aceptabilidad del comportamiento disfuncional. También identificamos que el nivel de ética del consumidor, la percepción del riesgo al replicar el comportamiento y la distancia social actúan como condicionantes del efecto de la proporción del daño en la probabilidad de replicar el comportamiento disfuncional.

PALABRAS CLAVE / Comportamiento disfuncional, efecto dominó, ética, percepción del riesgo, efecto de contagio. 


\section{INTRODUCTION}

In the retail context-offline or online-customers constantly interact and are influenced by other customers. These interactions and influences happen through conversations and observations (Libai et al., 2010) and can be either positive for companies, as customers can influence each other to buy or spread positive word-of-mouth, or cause damage because there are customers who behave dysfunctionally (Wilkes, 1978; Fullerton \& Punj, 1993; Daunt \& Greer, 2015).

Dysfunctional customer behavior (DCB), also called aberrant, unethical, or dishonest behavior, is understood as "actions by customers who intentionally or unintentionally, overtly or covertly, act in a manner that, in some way, disrupts otherwise functional service encounters" (Harris \& Reynolds, 2003, p. 145). DCB has also been described as client behaviors that violate conduct rules and norms generally accepted in consumption situations (Fullerton \& Punj, 1993). In these cases, customers break the rules established by the company or society and cause damage to companies, employees, themselves, and other customers. The types of DCB studied in marketing relate to behaviors such as shoplifting, purchasing counterfeit products, fraudulent return of merchandise, verbal or physical aggression, and vandalism (Fisk et al., 2010).

The interactions between dysfunctional customers and other customers can cause, among others, the domino effect, which is the dissemination of the dysfunctional behavior from a dysfunctional client to other nearby clients (Harris \& Reynolds, 2003). The possibility of the domino effect in the DCB has been explored (e.g., Harris \& Reynolds, 2003; Wu, 2007, 2008; Liao, Chou, \& Lin, 2015). In general, previous studies assume and find that if a customer sees another one engaging in a DCB, he/she may replicate this behavior. However, these studies do not explore the role of the amount of damage to the company affected by the DCB. For example, will a customer replicate a DCB from another customer if the damage to the company is significant? What if the damage to the company is minimal?

The present study aims to verify if the amount of damage can influence the occurrence of the dysfunctional behavior's domino effect. We suppose that a customer, having interacted with a dysfunctional customer, is more likely to repeat this behavior if the damage is minimal than when it is great. This domino effect may be a consequence of DCB acceptability-that is, the greater the acceptability of a DCB, the greater the likelihood of imitation of the deviant behavior.

To better understand the damage amount effect, we investigated three conditions that could change the likelihood of the domino effect according to the level of damage to the company: the level of customer ethics, the perceived risk, and the social distance. Specifically, we expect that higher levels of customer ethics and perceived risk can mitigate the effects of the amount of damage on the likelihood of the DCB's domino effect. Similarly, we expect that an in-group condition (vs. outgroup condition from social distance) could reduce the contagion effect of the DCB.

Notably, explanations for these imitative behaviors are studied by psychologists through social learning theory (Bandura, 1977) and by criminologists through broken windows theory (Schaefers, Wittkowski, Benoit, \& Ferraro, 2016). Marketing studies also explore the mechanisms of observational learning, or how customers not only observe the behaviors of others but how they learn this behavior, and how these imitative effects influence consumer preferences and decisions (Libai et al., 2010).

This paper first discusses the theoretical foundations of the domino effect of DCB and the hypotheses. Next, we carry out five experimental studies to test the hypotheses. Finally, we offer theoretical and practical implications.

\section{THEORETICAL BACKGROUND AND HYPOTHESES}

Bandura (1963) argues that when a model is provided, behavioral patterns quickly emerge; unlike the longer instrumental training process, studies on imitation demonstrate that exposure to negative models (e.g., aggressive) implies an increase in subsequent responses. Imitation behavior refers to participating in an action after observing similar behavior by others (Akers \& Sellers, 2004). Whether the behavior modeled will be imitated depends on the characteristics of the models, the behavior observed, and the observed consequences of the behavior (Akers \& Sellers, 2004).

In the context of complaints, Kowalski (1996) presents similar results on the domino effect. He calls it the "contagion of complaints" and concludes that, for various reasons, after an individual's complaint, the incidents of people complaining tend to increase. Akers and Sellers (2004, p. 92) relate that the relationship between social learning variables (i.e., social contagion or the domino effect) and criminal behavior (i.e., similar to DCB) is typically strong to moderate. Most customers may file modestly inflated claims that can still be justified by selfserving fairness perceptions to allow self-concept maintenance (Wirtz \& McColl-Kennedy, 2010). However, some may try to cheat for maximum benefit. 
Imitation can be an influencer of this customer opportunistic complaint behavior (Baker, Magnini, \& Perdue, 2012). Gino, Gu, and Zhong (2009) investigated the imitative effect and found that observing colleagues who acted unethically, such as cheating in a test, increases the observer's level of unethical behavior. A person's behavior can be contagious if it induces other people to act similarly (Schaefers et al., 2016). Based on the broken windows theory of criminology, they studied the contagious effects of DCB and found that anonymity encourages dysfunctional behaviors in access based car services. The broken windows theory proposes that urban deterioration signals previous misconduct and generates criminal activities, predicting the contagion of dysfunctional behavior; that is, for bad behavior to occur, it is not necessary for the person to witness past misbehavior (Schaefers et al., 2016) but only to realize that it has succeeded.

Moreover, the amount of damage caused may influence the probability of the domino effect. Specifically, behaviors that result in minor damages to businesses can be more easily accepted by people and, therefore, more easily imitated by other customers, thus increasing the likelihood of the domino effect.

$\mathrm{H}_{1}$ : The amount of damage caused to the company influences the probability of the domino effect of a previous DCB, so the probability is higher (lower) when the damage is minimal (great).

$\mathrm{H} 2$ : The relationship between the damage amount and subsequent $D C B$ is mediated by the acceptability of the DCB.

The level of moral development is an individual's psychological characteristic, and moral restraints are a way to check if a behavior is right or wrong (Fullerton \& Punj, 1993). These restrictions may play an important role in making each individual perceive a dysfunctional act as either moral or immoral.

Fullerton, Kerch, and Dodge (1996) indicate that the acceptance of unethical behavior by an individual is attributed more to the situation than to their attitude. Thus, although individuals perceive behaviors as unethical, depending on the situation, tolerance in the ethical judgment of certain behaviors may vary.

Following these observations, we believe that the customer ethics level plays an important role in the replication of dysfunctional behaviors. Specifically, for individuals with higher levels of ethics, an increase in company damage represents a lower DCB acceptability, or a decrease in the intention to perform a subsequent DCB.
H3: The level of customer ethics moderates the domino effect, so for higher levels of ethics, the effect of the amount of damage on DCB acceptability will be negative.

Even with important motivational variables that influence individuals to repeat dysfunctional behaviors, the fear of being caught may deter them. Albers-Miller (1999) points out that despite the financial advantages that dysfunctional behavior offers, criminal penalties can discourage such actions. That is, the lower the risk of detention, the greater the likelihood of dysfunctional behaviors.

Likewise, Daunt and Greer (2015) found that the likelihood of a customer stealing a product in a store is lower when this store is under surveillance. Therefore, an opportunity to assume a dysfunctional behavior is the result of a set of favorable conditions that offer rewards and do not present punishments (Ferrell \& Gresham, 1985). If the client perceives the opportunity, he will be more prone to act dysfunctionally.

The motivating or inhibiting factor of perceived risk is also influenced by previous client experiences. Daunt and Harris (2011) point out that the behavior of deviant clients who were successful in the past is associated with performing the same acts in the future. When the customer realizes that they have a high chance of success (low perception of risk) after dysfunctional behavior, they merge past and future behaviors.

$\mathrm{H}_{4}$ : Perceived risk moderates the domino effect, so that a higher perceived risk (vs. perceived low risk) will decrease the likelihood of the domino effect under a high damage condition.

A consumer who engages in some type of DCB can be motivated by financial gain, revenge, dissatisfaction, or just taking advantage of a company's failure (Wirtz \& Kum, 2004). Opportunistic consumer behavior can take several forms, including inflated and fake insurance claims (Wirtz \& McColl-Kennedy, 2010). The findings of a study from Wirtz and McColl-Kennedy (2010) indicate that consumers tend to exaggerate claims when they complain about damage caused by a company.

Gino, Ayal, and Ariely (2009) found support for the idea that when the saliency of dishonesty increases, cheating decreases. Some claimants may try to maximize the compensation they seek to obtain; however, many opportunistic claims are likely to be less than the maximum amount possible, so that claimants maintain their positive self-concept (Mazar, Amir, \& Ariely, 2008a). The ambiguity associated with what constitutes fair compensation enables a self-serving interpretation (Babcock \& Loewenstein, 1997) while allowing claimants to perceive themselves as not being dishonest (Mazar, Amir, \& Ariely, 2008b). 
H5: Customers exposed to a successful DCB with high damage will claim a higher value to the company than customers exposed to a successful DCB with low damage.

The social-norms theory (Tajfel, 1982) shows an important factor that might influence the degree to which people are affected by the unethical behavior of those around them: the degree to which they identify with them. The idea is that when the identification is strong, the behaviors of others will have a higher influence on observers' social norms. When an in-group member is observed engaging in unethical behavior, other group members may make him or her the standard for the descriptive norm and, as a result, engage in unethical behavior themselves (Gino, Ayal, \& Ariely, 2009).

However, another stream of research found that a proximal identification between customers could mitigate the contagion effects from the DCB (Schaefers et al., 2016). This research is supported by the notion of community, in which a member of the community tries to reestablish the order after another person's misbehavior in the group. Sampson, Morenoff, and Gannon-Rowley (2002) found that social ties can be an informal control mechanism for misbehavior in a group. Therefore, individuals evaluate in-group members (socially close ones) that misbehave more negatively than out-group members with the same behavior (Gino, Gu, \& Zhong, 2009). Based on this evidence, we propose that:

H6: Social distance moderates the domino effect, so that being a member of an in-group (vs. out-group) will decrease the likelihood of the domino effect.

To test our hypotheses, we conducted five experimental studies. Studies $1 A$ and $1 B$ tested the effect of the amount of damage on the likelihood of replicating a DCB and examined the mediator role of $D C B$ acceptability and the ethics level moderation. Studies $2 \mathrm{~A}$ and $2 \mathrm{~B}$ replicated the domino effect and evaluated how the perception of risk influences the relationship between the amount of damage and the likelihood of replicating a DCB. In Studies $1 A$ and $2 A$, we tested as a dependent variable the likelihood of replicating a DCB, and in Studies $1 B$ and $2 B$, we tested as a dependent variable the amount of money that the participant requested after being exposed to a successful DCB. Study 3 replicated the domino effect and evaluated how the perception of risk influences the relationship between the amount of damage and the likelihood of replicating a DCB and examined the moderator effect of social distance (in-group vs. out-group).

\section{STUDY 1A}

The goal of Study $1 \mathrm{~A}$ was to test the effect of the amount of damage (minimal vs. great) on the likelihood of replicating a dysfunctional behavior using an insurance claim scenario. We theorized that when a customer reports a "padded" insurance claim, he/she will exhibit more dysfunctional behavior when the amount of damage is low (vs. high). In addition, we examined the mediator role of dysfunctional behavior acceptability (Neale \& Fullerton, 2010) and the moderator role of the ethical level (Muncy \& Vitell, 2005).

\section{Study design and method}

The study manipulated a between-subject factor (damage: low advantage vs. high advantage) and used the continuous measure of the probability of the domino effect. Seventy-nine participants $\left(M_{\text {age }}=41.74\right.$ years old; $S D=13.38 ; 53.2 \%$ female $)$ were recruited from Amazon's Mechanical Turk with monetary compensation.

Procedures and stimulus. The participants read a scenario about dysfunctional behavior in an insurance claim based on Miyazaki (2009). The stimulus was based on a third consumer (Bill) who reported a dysfunctional behavior regarding an insurance claim to his friend (Sam). Subjects had heard a report of a "padded" insurance claim made weeks earlier. This is an important fact in the scenario because it allowed the occurrence of the domino effect to stem from listening to the report of another dysfunctional customer.

Inside the scenario, two conditions were presented between subjects: low damage vs. high damage. Then, subjects were presented with the following situation: "On a recent trip, Sam had his suitcase stolen. While completing the claim for the insurance company, Sam remembered that the same case happened to his friend Bill a couple of weeks ago. Bill told Sam that he made a claim for $\$ 750$ (vs. the maximum $\$ 3,000$ ) instead of the actual loss of about $\$ 500$. Because of that, Sam felt comfortable 'padding' the insurance claim, as well. He believed it was acceptable to increase a claim for a low (vs. high) amount to make up for the deduction (vs. insurance premium) of \$250. The insurance company had accepted Bill's claim and he received $\$ 750$." The values used for the claims were based on real data extracted from Miyazaki (2009).

Next, they were asked about the probability of the domino effect, measured by a 7 -point scale $(1=$ not at all likely to $7=$ extremely likely) for the two situations. The first measured the likelihood of another person (Sam) replicating a dysfunctional behavior through the question "What is the likelihood that Sam would repeat Bill's behavior?" The second item, "How likely 
are you to repeat Bill's behavior?" measured the probability of the subject replicating Bill's dysfunctional behavior. These measures were based on Daunt and Greer (2015). To perform the manipulation check, we asked, "How much do you think Bill took advantage of the value of the lost items?” ( $1=$ a little to $7=$ a lot), followed by the mediation variable "How acceptable do you think his behavior was in the situation?" (1= completely unacceptable to $7=$ completely acceptable) based on Neale and Fullerton (2010). After that, we applied the consumer ethics scale (CES), "defined as the moral principles and standards that guide the behavior of individuals or groups as they obtain, use, and dispose of goods and services" by Muncy and Vitell (2005, p. 268) to verify the moderating effect of individual ethical behavior. This was on a 7-point scale with 31 items ( 1 = strongly believe that it is wrong and $7=$ strongly believe it is not wrong) $(a=.916)$. At the end, participants answered a few demographic questions and were extensively debriefed.

Pretest. We pretested our stimuli to ensure that the dysfunctional behaviors acceptability would have different perceptions in relation to the damage amount. The participants read the scenario about dysfunctional behavior in an insurance claim based on Miyazaki (2009). In this scenario, participants read about a situation in which one customer had their suitcase stolen. The manipulation check was the same as the main study. Participants indicated on a 7-point scale "How much do you think he took advantage of the value of the lost items?" ( $1=$ a little to 7 = a lot) and "How acceptable do you think his behavior was in the situation?" ( 1 = completely unacceptable to 7 = completely acceptable) based on Neale and Fullerton (2010).

Seventy M-Turk panelists completed the pretest. Ten participants whose native language was not English were excluded from the final sample. Thus, the final sample included 60 participants $\left(M_{\text {age }}=36.23 ; 50 \%\right.$ male). An independent t-test was performed to compare the mean for the small advantage $\left(M_{\text {small_advantage }}=5.93, S D=1.484\right)$, which was significantly lower than the large advantage $\left(M_{\text {large_advantege }}=6.80, S D=0.487, t(58)=\right.$ 3.041, $p=.004)$, and the high damage of DCB's acceptability $\left(M_{\text {high }}\right.$ damage $=1.363 ; S D=2.080)$, which was significantly lower than for low damage $\left(M_{\text {low_damage }}=2.87 ; S D=1.73, t(58)=2.496, p=.015\right)$. Thus, the pretest indicated that the scenarios about the insurance claim were perceived as different among the participants.

\section{Results}

Manipulation check. We verified that subjects in the large amount of damage condition (or higher advantage) $(M=6.59)$ perceived that Bill took more advantage than subjects in the low amount of damage condition (or lower advantage) $(M=5.30 ; F(1,77)=$ 16.880; $p<.001)$

Domino effect. Subjects exposed to the high amount of damage condition $(M=4.56)$ indicated a lower probability that Sam would repeat Bill's behavior than subjects exposed to the low amount of damage condition $(M=5.45 ; F(1,77)=7.389 ; p$ <.01). Additionally, the subjects in the high amount of damage condition ( $M=2.25$ ) indicated a lower likelihood of themselves replicating Sam's behavior than participants in the low amount of damage condition $(M=3.52 ; F(1,77)=7.858 ; p<.01)$.

Moderated-mediation. To verify if the acceptability of the DCB explains why the domino effect happens, and how the participants' ethics level influences this relationship, we ran a moderated-mediation analysis following Hayes' (2013) recommendations. First, we dummy coded the amount of damage ( $0=$ low and $1=$ high) for the independent variable. The mediator was the acceptability of the DCB, and the dependent variable was the likelihood that Sam would replicate Bill's behavior. We also used the subjects' ethics level as the moderator of the relationship between the amount of damage and the mediator.

There is a significant effect of the interaction between the amount of damage and ethics level on acceptability $(a=-.36$; $t$ $=-2.45 ; p<.05)$. This result indicates that the acceptability of the DCB depends on the amount of damage moderated by the ethics level. On the other side, the mediation effect of the likelihood that Sam would replicate Bill's dysfunctional behavior was positive ( $b$ $=.18 ; t=2.03 ; p<.05$ ). The indirect effect is significant only in the high levels of ethics (one SD above the mean). In this condition, through 5,000 resamples from bootstrapping, the indirect effect $(a \times b=-.11)$ is found to be negative and significant because the confidence interval (95\%) did not present a null effect (-.31 to -.01). The significance of the direct effect of the amount of damage on the likelihood of the domino effect $\left(c^{\prime}=-.33 ; t=-1.98 ; p=.05\right)$ indicates that there is a partial mediation.

Likewise, we tested the mediation role of the acceptability in the relationship between the amount of damage and the likelihood of the subject to replicate Sam's behavior. As in the first test, we also considered the level of ethics as the moderator of the relationship between the amount of damage and the acceptability.

For the moderated-mediation model, the effect of the interaction between the amount of damage and ethics level on acceptability ( $a=-.36 ; t=-2.45 ; p<.05)$ is the same as in the first analysis. The effect of the mediator on the likelihood that a subject would replicate Sam`s dysfunctional behavior was positive ( $b=$ .92; $t=11.65 ; p<.001)$. The indirect effect is also significant but only in high levels of ethics (one SD above the mean). Specifically, 
through 5,000 resamples from bootstrapping, the indirect effect $(a \times b=-.57)$ is found to be negative and significant because the confidence interval (95\%) did not present a null effect (-.96 to $-.15)$. Unlike the first moderated-mediation model, the direct effect of the amount of damage on the likelihood of the domino effect $\left(c^{\prime}=-.10 ; t=-.72 ; p=.47\right)$ is not significant, which indicates that the effect of the amount of damage on the domino effect is fully explained by the acceptability of the DCB.

To improve the understanding of the levels of ethics moderation in the relationship between the amount of damage and the acceptability of the customer dysfunctional behavior, we performed a Johnson-Neyman test to determine the location of the effect of damage significance on the acceptability, considering the level of ethics as a moderator, as shown in Graphic 1.

\section{Graphic 1. Effect of damage significance on acceptability with ethics as moderator - Study $1 \mathrm{~A}$}

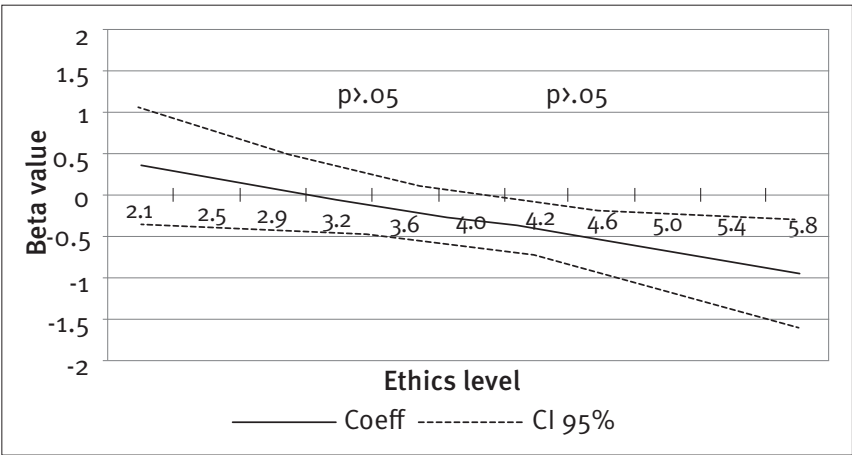

\section{Discussion}

Study $1 A$, supporting $H_{1}$, identified that the likelihood of replicating a DCB is higher in conditions that result in a lower amount of damage to the company. Specifically, the intention to replicate the behavior of another client is more pronounced when the subjects perceive that this behavior has minimal negative consequences to the company.

As predicted by $\mathrm{H} 2$, we also verified that the acceptability of the previous DCB mediated the influence of the amount of damage on the domino effect. The negative path between the amount of damage and the acceptability indicates that the higher the amount of damage to the company, the less acceptable the behavior, and, consequently, the probability that the client will replicate this behavior is lower.

In addition to the mediation effect, the level of ethics modifies how the amount of damage influences the acceptability, supporting $\mathrm{H}_{3}$. Specifically, for subjects with higher levels of ethics, the effect of the amount of damage on the acceptability of the $D C B$ is negative, indicating that for these subjects, ethics reduce the acceptability of the DCB with the amount of damage increase more than for subjects with lower levels of ethics.

\section{STUDY 1B}

Study $1 \mathrm{~B}$ was designed to be similar to Study $1 \mathrm{~A}$ but used a different dependent variable measure. We measured it with a metrical scale from $\$ 500$ to $\$ 3,000$. Using this measure, we can verify how much money customers would claim from their insurance and if they are influenced by other customers. We show that this is influenced by the customer ethics level and the acceptability of the DCB. The aim of this study is to test hypotheses 1 and 5 .

\section{Study design and method}

In this study, one factor, on two different levels, was manipulated (damage: low advantage vs. high advantage) in a between-subject design measuring the amount of the claim (domino effect). Ninetythree participants were recruited from an online panel (Amazon Mechanical Turk, $M_{\text {age }}=34.38$ years old; $S D=9.90 ; 55.9 \%$ male) in exchange for monetary compensation.

Procedures and stimulus. The procedure was identical to Study $1 \mathrm{~A}$ with one important modification-damage manipulation participants answered only one question related to the dependent variable: "How about you? How much money would you ask for from the insurance company in a similar situation?" It was measured with a metrical scale from $\$ 500$ to $\$ 3,000$. The acceptability of the DCB mediation and CES ( $a=$ .942) moderation followed the same procedures as in Study $1 \mathrm{~A}$. At the end, participants answered a few demographic questions and were extensively debriefed.

\section{Results}

Manipulation check. Participants in the high amount of damage condition (or higher advantage) $(M=5.63)$ perceived that Bill took more advantage than subjects in the low amount of damage condition (or lower advantage) $(M=4.67 ; F(1,91)=8.032 ; p<.01)$.

Domino effect. The participants in the large amount of damage condition (or higher advantage) $(M=1,457.10)$ indicated that they would ask for more money from the insurance company than participants in the low amount of damage condition (or lower advantage $)(M=833.45 ; F(1,91)=16.634 ; p<.001)$. 
Moderated-mediation. To verify how the interaction between the amount of damage and ethics of the participant influence the acceptability of the DCB and how this acceptability influences the domino effect, we used a moderated-mediation model, as in Study $1 \mathrm{~A}$. However, the dependent variable in this study was the amount of money requested by the participant in the insurance claim.

The path between the interaction and acceptability was significant ( $a=-.71 ; t=-2.09 ; p<.05$ ), indicating that the amount of damage and ethics interaction influences the acceptability of the DCB. The acceptability positively influences the domino effect $(b=207.66 ; t=5.74 ; p<.001)$, suggesting that an increase in the acceptability leads to higher amounts of money asked for from the insurance company by the participant.

The indirect effect was only significant in the higher ethics levels (one SD above the mean); through 5,000 resamples from bootstrapping, this effect ( $a \times b=-237.68$ ) is shown to be negative and significant because the confidence interval (95\%) did not present a null effect $(-508.21$ to -43.43$)$. The significance of the direct influence of the amount of damage on the domino effect $\left(c^{\prime}=699.62 ; t=5.29 ; p<.001\right)$ indicates that there is a partial mediation, or the acceptability partially mediates the influence of the amount of damage on the domino effect, considering the level of ethics as a moderator, as shown in Graphic 2.

\section{Graphic 2. Effect of damage significance on acceptability with ethics as moderator - Study $1 B$}

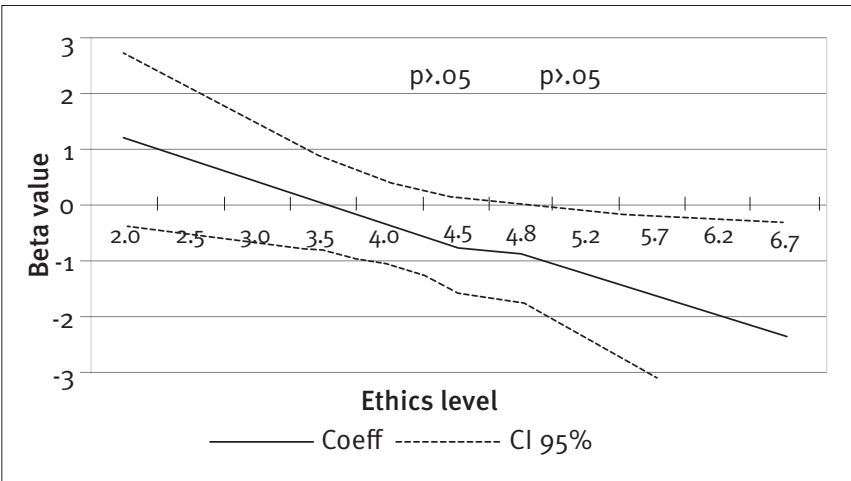

To specify how the level of ethics of the participant modifies their acceptability of DCB, we used the Johnson-Neyman test. Regarding the significance of the effect of damage on the acceptability, as a moderator, levels of ethics above 4.77 (7-point scale) indicate a negative and significant effect of the amount of damage on the acceptability. However, there is no relationship between the amount of damage and acceptability for levels of ethics below 4.77 .

\section{Discussion}

The findings of this second study support the assumption of $\mathrm{H}_{5}$. Specifically, subjects exposed to a DCB in which the previous customer asked for a high amount from the company adjusted their claim and also asked for a higher amount than subjects who were exposed to a previous customer asking for a low amount. This finding supports the logic that customers anchor and adjust their future behavior according to previous behavior from another customer.

Moreover, we support the findings from Study $1 \mathrm{~A}$ for the underlying mechanism, showing that acceptability is the mechanism that explains how previous DCB influences the domino effect. We also support the role of customer ethics, which moderates the relationship between previous behavior and the likelihood of the domino effect.

\section{STUDY 2A}

The goal of Study $2 \mathrm{~A}$ was to replicate the domino effect and evaluate how risk perception (low vs. high) influences the relationship between the amount of damage and the likelihood of replicating a dysfunctional behavior. We predicted that when the subject perceives a high (vs. low) risk, it means there is a higher probability that the behavior can be discovered and punished by the company, thereby reducing the intention to replicate a dysfunctional behavior in the high amount of damage condition. The aim of this study is to test hypothesis 4 .

\section{Study design and method}

Study $2 \mathrm{~A}$ was a 2 (damage: low advantage vs. high advantage) $\times$ 2 (risk perception: low vs. high) between-subjects design. One hundred and twenty-one participants were recruited online (Amazon Mechanical Turk, $M_{\text {age }}=38.78$ years old; $S D=12.20$; $58.7 \%$ female) in exchange for monetary compensation.

Procedures and stimuli. Study $2 \mathrm{~A}$ had the same procedures as Study $1 \mathrm{~A}$, with some important modifications, such as the risk perception stimuli between scenarios. In the low damage scenario (vs. high), the low risk perception was manipulated through the following information that participants received: “There is a clause in their contracts that do not allow the insurance company to use airports' $x$-ray videos for examining the application of the customer. The insurance company accepted Bill's claim, and he received $\$ 750$ (vs. the maximum \$3,000)." In the high damage scenario (vs. low), the high risk perception was manipulated 
as follows: "There is a clause in their contracts that allows the insurance company to use airports' $x$-ray videos for examining the application of the customer; in case cheating is detected, the insurance company is not obligated to indemnify the customer. The insurance company accepted Bill's claim, and he received \$3,000 (vs. \$750)." The manipulation check question regarding the amount of advantage was measured on a 7-point scale: "How much do you think he took advantage of the value of the lost items?" ( $1=$ a little to $7=\mathrm{a}$ lot). Risk perception was measured through two items from Blais and Weber (2006) on a 7-point scale. At the end, participants answered a few demographic questions and were extensively debriefed.

\section{Results}

Manipulation check. We verified that participants in the high amount of damage condition (or higher advantage) $(M=5.89)$ perceived that Bill took more advantage than subjects in the low amount of damage condition (or lower advantage) $(M=5.38 ; F(1$, 119) $=4.122 ; p<.05)$. Likewise, subjects exposed to the lower risk condition $(M=3.76)$ perceived that the risk of Sam following Bill's behavior is lower than subjects exposed to the higher risk condition $(M=4.21 ; F(1,119)=4.282 ; p<.05)$.

Perceived risk moderation. We found a significant effect of the interaction between the amount of damage/advantage and perceived risk on the probability of Sam repeating Bill's behavior $(F(1,117)=4.329 ; p<.05)$. Specifically, there is no difference in the domino effect along the low damage condition $\left(M_{\text {lower_risk }}=5.13 ; M_{\text {higher_risk }}=5.18 ; F(1,117)=.022 ; p=.883\right)$, but there is a difference in the domino effect along the high damage condition $(F(1,117)=7.638 ; p<.01)$. Therefore, subjects exposed to the higher risk indicated a lower probability $(M=4.23)$ of Sam replicating Bill's behavior than subjects exposed to the lower risk condition $(M=5.27)$.

To complete the model, we ran a pairwise comparison of the amount of damage effect along the risk perception conditions. The participants exposed to the lower risk condition did not present a significant difference in the perceptions related to Sam following Bill's behavior (e.g., domino effect) $\left(M_{\text {high_damage }}\right.$ $\left.=5.27 ; M_{\text {low_damage }}=5.13 ; F(1,117)=.143 ; p=.706\right)$. However, participants exposed to the higher risk condition had different judgments about Sam's behavior $(F(1,117)=6.718 ; p<.01)$. In the high damage condition, respondents indicated a lower probability of Sam replicating Bill's behavior $(M=4.23)$ than in the low damage condition $(M=5.18)$. These findings are presented in Graphic 3.

\section{Graphic 3. Sam's domino effect}

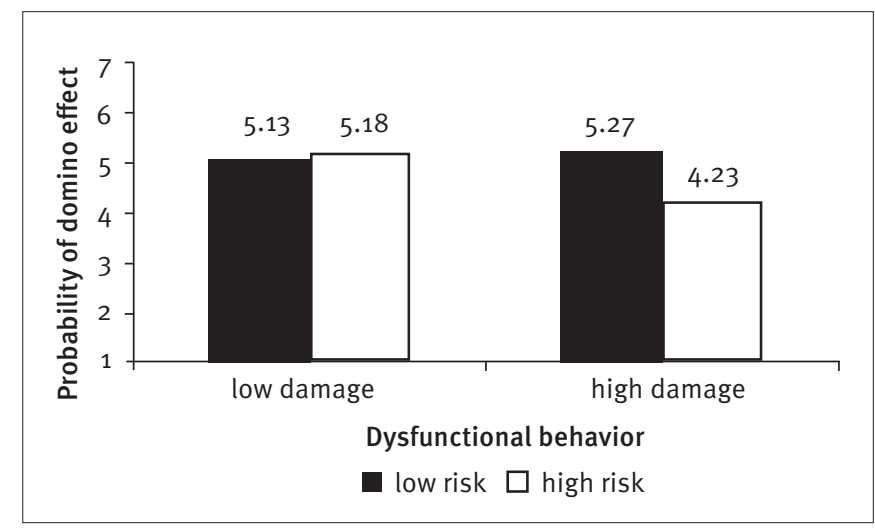

We also verified how the amount of damage and the risk perception influence the behavioral intentions of the respondent. There is a significant effect of the interaction on the probability of the respondent to replicate Bill's behavior $(F(1,117)=4.640 ; p<$ .05). Specifically, there is a marginal difference in the likelihood of the respondent to repeat Bill's behavior in the low amount of damage condition $(F(1,117)=3.365 ; p=.06)$ because subjects exposed to higher risk indicate a higher probability $(M=3.25)$ of repeating Bill's behavior than subjects exposed to a lower risk condition $(M=2.43)$. There is no difference in the probability along the high amount of damage condition $(F(1,117)=1.487 ; p=.22)$.

Nevertheless, there is a significant difference in the probability of repeating Bill's behavior in the higher risk condition $(F(1,117)=6.292 ; p<.05)$. In this condition, subjects exposed to a low amount of damage presented a higher probability $(M=$ 3.25) of engaging in the domino effect than subjects in the high amount of damage $(M=2.13)$. It is important to note that there is no difference along the lower risk condition $(F(1,117)=.316$; $p=.57$ ). Graphic 4 presents these findings.

\section{Graphic 4. Participants’ domino effect: Probability}

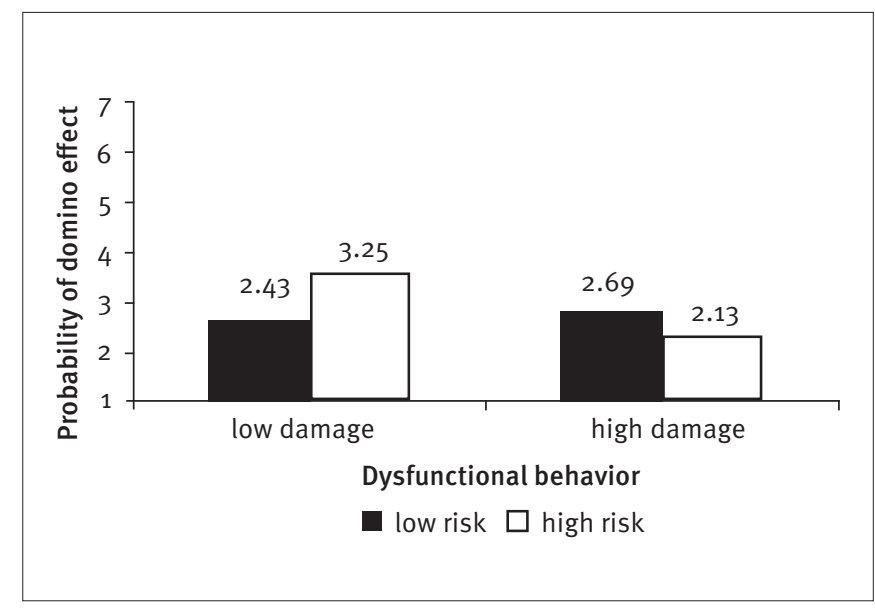




\section{Discussion}

There is evidence that the level of perceived risk influences the relationship between the amount of damage and the domino effect. This finding supports $\mathrm{H}_{4}$. When the subject perceives a high risk, it means there is a higher probability that the behavior can be discovered and punished by the company. In this case, the customer reduces the intention to replicate a DCB in the high amount of damage condition. However, it is interesting to note that the perceived risk did not influence the domino effect in the low amount of damage condition. This should be explored in future studies, as it is possible that in the low amount of damage condition, the domino effect can be easily justifiable when compared to the high amount of damage, in which the advantage taken by the client is larger.

\section{Study 2B}

Study $2 B$ was designed to replicate Study $2 A$, using a dependent variable measure from Study $1 B$. We used a metrical scale from $\$ 500$ to $\$ 3,000$. We replicated the same mechanism evaluated in Studies $1 \mathrm{~A}$ and $1 \mathrm{~B}$ and showed the relationship between the customer ethics level and the acceptability of the DCB.

\section{Study design and method}

Study 2 B was a 2 (damage: low advantage vs. high advantage) $\times 2$ (risk perception: low vs. high) between-subjects design. The 181 participants were recruited online (Amazon Mechanical Turk, $M_{\text {age }}=33.72$ years old; $S D=10.06 ; 61.9 \%$ male) in exchange for monetary compensation.

Procedures and stimulus. The procedure was identical to Study 2A. However, . participants answered the same dependent variable question from Study $1 \mathrm{~B}$, using a metrical scale from $\$ 500$ to $\$ 3000$. The manipulation check and acceptability of the DCB mediation were the same as Studies $1 B$ and $2 \mathrm{~A}$. At the end, participants answered a few demographic questions and were extensively debriefed.

\section{Results}

Manipulation check. The subjects in the high amount of damage condition (or higher advantage) $(M=5.78)$ perceived that Bill took more advantage than subjects in the low amount of damage condition (or lower advantage) $(M=5.12 ; F(1,179)=11.003 ; p$ (.05). We also verified that subjects exposed to the lower risk condition ( $M=3.76$ ) perceived that the risk of Sam following Bill's behavior was lower than subjects exposed to the higher risk condition $(M=4.21 ; F(1,119)=4.282 ; p<.05)$.

Perceived risk moderation. We analyzed how the amount of damage and the perception of risk influence the amount of money requested by the respondents. There is a significant effect of the interaction between the amount of damage and the perception of risk on the probability of Sam repeating Bill's behavior ( $F(1$, 177) $=8.838 ; p<.01$.

Along pairwise comparisons, subjects in the low amount of damage condition do not present differences in the risk perceptions conditions $(F(1,177)=.145 ; p=.70)$. However, in the high amount of damage condition, subjects exposed to the lower risk perception $(M=1,559.06)$ indicate a higher value than subjects exposed to the higher risk perception $(M=1,021.77$; $F(1$, 177) $=15,324 ; p<.001)$.

In the risk perception conditions, there is a significant difference in the amount of money that the respondent would ask for in the lower risk perception $(F(1,177)=25.407 ; p<.001)$. In this condition, subjects exposed to a low amount of damage would ask for a lower amount $(M=838.61)$ than subjects exposed to the high amount of damage condition $(M=1,559.06)$. There is no difference regarding the higher risk condition $(F(1,177)=.853$; $p=.35)$. Graphic 5 presents these findings.

\section{Graphic 5. Participants' domino effect: Amount of money request}

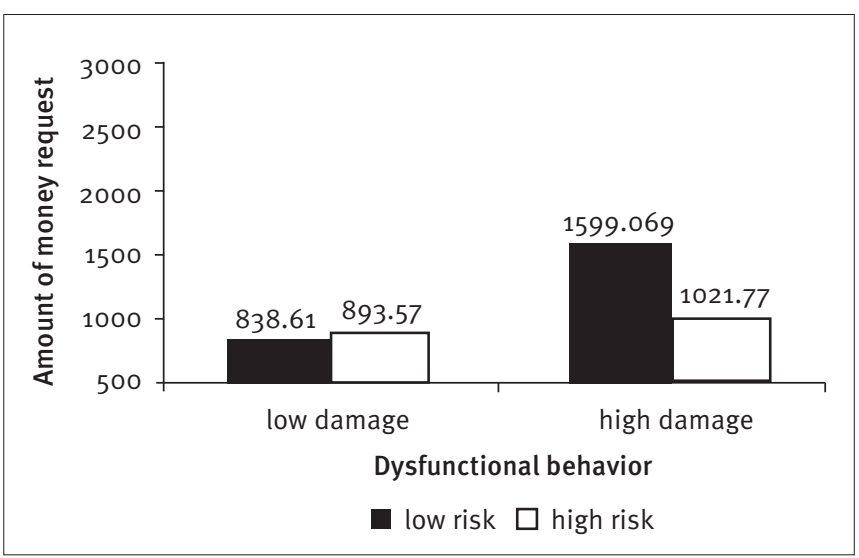

Moderated-mediation. Considering that the acceptability of the $D C B$ was tested as the underlying mechanism in the first study, in Study $2 \mathrm{~B}$, we also included this variable in the relationship between the interaction among damage and risk and the amount of money that the participant requested.

The path between the interaction and the behavior's acceptability is significant ( $a=-1.21 ; t=-2.05 ; p<.05)$, indicating that the amount of damage and risk perception interaction 
influence the acceptability of the DCB. The acceptability positively influences the domino effect $(b=171.05 ; t=7.61 ; p<.001)$.

The indirect effect is only significant in the higher levels of risk perception; through 5,00o resamples from bootstrapping, this effect ( $a \times b=-231.39)$ is shown to be negative and significant because the confidence interval (95\%) did not present a null effect (-410.01 to -88.22). Additionally, the significance of the direct effect of the amount of damage on the domino effect ( $c$ ' $=$ $549,58 ; t=6.00 ; p<.001)$ indicates a partial mediation.

\section{Discussion}

This study provides additional support to $\mathrm{H}_{2}, \mathrm{H}_{3}, \mathrm{H}_{4}$, and $\mathrm{H}_{5}$. Specifically, the results of Study $2 \mathrm{~B}$ indicate that the acceptability of the DCB mediates the effect of the amount of damage on the domino effect (measured by the value claimed to the company); the level of ethics and the perception of risk act as boundary conditions of the occurrence of the domino effect.

\section{STUDY 3}

The goal of Study 3 was to test the domino effect and evaluate how risk perception (low vs. high) and social distance (in-group vs. out-group) influence the relationship between the amount of damage and the likelihood of replicating a dysfunctional behavior. The aim of this study was to test hypothesis 6 .

\section{Study design and method}

Study 3 had a 2 (damage: low advantage vs. high advantage) $\times 2$ (risk perception: low vs. high) $\times 2$ (social distance: in-group vs. outgroup) between-subjects design. Participants in the experiment were 167 undergraduate students from a Brazilian university $\left(M_{\text {age }}\right.$ $=29.28$ years old; $S D_{a g e}=8.77 ; 51.5 \%$ female). They did not receive any compensation.

Procedures and stimulus. The procedure was identical to that of Study $2 \mathrm{~B}$ with one important modification-the social distance stimuli between scenarios. In the in-group condition (vs. out-group), participants received the following extra information: "While completing the claim for the insurance company, he remembered that the same case happened to his brother a few days ago. His brother told him that he had applied for compensation." The out-group scenario was manipulated as follows: "While filling out the claim form, he remembered that this same situation had occurred with a passenger sitting in the back row during his one-way flight. He listened to the passenger telling the person on the side about his claim for compensation." Later, the scenario manipulation participants answered the following dependent variable question: "How much money would you ask for from the insurance company in a similar situation?" This question was measured with a metrical scale of $R \$ 375$ to $R \$ 4,520$. This value was adapted to the Brazilian participants; we used the proportional value based on the maximum value $(R \$ 4,520)$ proposed by the Montreal convention (Morsello, 2004). The manipulation check question about social distance was measured on a 7-point scale: "How close am I to the person who made the claim before him?" ( $1=$ too far to $7=$ too near). At the end, participants answered a few demographic questions and were extensively debriefed.

\section{Results}

Manipulation check. We verified that subjects in the high amount of damage condition (or higher advantage) $(M=5.26 ; S D=1.90)$ perceived that Bill took more advantage than subjects in the low amount of damage condition (or lower advantage) $(M=4.31$; $S D=1.85 F(1,165)=10.579 ; p<.001)$. Subjects exposed to the lower risk condition $(M=3.07 ; S D=1.81)$ also perceived that the risk of Sam following the domino behavior was lower than subjects exposed to the higher risk condition $(M=4.05 ; S D=$ 1.77; $F(1,165)=12.472 ; p<.001)$. Likewise, subjects exposed to the in-group condition $(M=5.68 ; S D=1.69)$ perceived that the social distance from the other passenger was lower than subjects exposed to the out-group condition $(M=2.29 ; S D=1.66 ; F(1$, 164) = 169.63; $p<.000)$.

Domino effect. Subjects exposed to the high amount of damage condition (or higher advantage) $(M=2,105.58)$ indicated that they would ask for more money from the insurance company than subjects exposed to the low amount of damage condition (or lower advantage) $(M=1,183.27 ; F(1,165)=22.550 ; p<.001)$.

Moderated-mediation. To verify how the interaction between the amount of damage and social distance influence the acceptability of the DCB and how this acceptability influences the domino effect, we used a moderated-mediation model, as in Study $1 \mathrm{~A}$. The dependent variable in this study was the amount of money asked for in the insurance claim by the participant (similar results were found with the projective measure as the dependent variable).

The path between the interaction and acceptability is significant ( $a=-.41 ; t=-3.11 ; p<.01)$, indicating that the amount of damage and social distance interaction influences the acceptability of the DCB. However, as social distance conditions 
the effect from the amount of damage, the effect is significant when the participant was exposed to the in-group condition $(a$ $=-.61 ; t=-3.25 ; p<.01)$ and non-significant when the participant was exposed to the out-group condition ( $a=.21 ; t=1.14 ; p=.25)$. Following the model, the acceptability positively influences the domino effect $(b=372.33 ; t=7.87 ; p<.001)$, indicating that an increase in the acceptability leads to higher amounts of money asked for from the insurance company by the participant.

The indirect effect is only significant in the in-group condition; through 5,000 resamples from bootstrapping, this effect ( $a \times b=-228.91$ ) is shown to be negative and significant because the confidence interval (95\%) did not present a null effect ( -373.72 to -88.47$)$. The significance of the direct effect of the amount of damage on the domino effect ( $c^{\prime}=532.56 ; t$ $=6.38 ; p<.001$ ) indicates that there is a partial mediation, or the acceptability partially mediates the effect of the amount of damage on the domino effect, considering the social distance as a moderator of this relationship.

Three-way moderation. We also tested a three-way moderation using the amount of damage, the social distance, and the risk perception. We verify that the social distance conditions the effect from the interaction between the amount of damage and risk perception on the domino effect $(F(1,159)=7.810 ; p<$ .01). Specifically, the effect presented in Study $2 \mathrm{~A}$ happens when the participant was exposed to the in-group condition $(F(1,79)$ $=4.569 ; p<.05)$. Subjects exposed to the low risk perception presented a higher claim amount when the amount of damage was higher $(M=2,509.08)$ than when the amount of damage was lower $(M=1,165.19 ; F(1,79)=12.772 ; p<.01)$. In the higher risk perception, there is no difference between the amount of damage conditions $(F(1,79)=.146 ; p=.703)$. In the same sense, when exposed to the out-group condition, the effect from the interaction on the domino effect was not significant $(F(1,80)=$ $3.252 ; p=.075)$.

\section{Discussion}

Study 3 provides additional support for $\mathrm{H}_{1}, \mathrm{H}_{2}, \mathrm{H}_{4}$, and $\mathrm{H}_{5}$. Specifically, the results of Study 3 indicate that social distance is an important variable in the DCB context. The social distance is capable of reducing the domino effect, supporting $\mathrm{H} 6$, when the subject feels that it is low (in-group). This result is aligned with the notion of community and the social control and balance established between members to keep social cohesion. Moreover, when the subject is exposed to the in-group, the risk perception conditions the effect of the amount of damage on the DCB.

\section{GENERAL DISCUSSION}

We respond to calls to investigate the processes underlying DCB (Fisk et al., 2010; Harris \& Reynolds, 2003). As previously discussed, the domino effect has not been adequately investigated empirically (e.g., Gino, Gu, \& Zhong, 2009; Schaefers, Wittkowski, \& Ferraro, 2016), and the main role of the amount of damage remained uncovered by the previous literature. We address this gap using four experimental studies that investigated both the amount of money the participant requested and the likelihood of replicating a dysfunctional behavior, going beyond common approaches (Fisk et al., 2010). We also investigated three distinct underlying mechanisms for these behaviors.

Our studies, supporting $\mathrm{H}_{1}$, identify that the likelihood of replicating a DCB is higher in a condition in which the $D C B$ results in a lower amount of damage to the company. Specifically, the intention to replicate the behavior of another client is stronger when the subject realizes that this behavior has minimal negative consequences to the company than when he/she perceives that the consequences to the company are greater. This evidence seems aligned with the capacity of justification of the customer (Wirtz \& McColl-Kennedy, 2010; Dootson, Neale, \& Fullerton, 2014). It is easier to justify a DCB when it causes less damage to the company than when it causes significant damage. Future studies could explore this underlying mechanism; however, it makes sense that great damage is considered more wrong than a small amount of damage.

As predicted by $\mathrm{H} 2$, we also found that the acceptability of the previous DCB mediates the effect of the amount of damage on the domino effect. The negative path between the amount of damage and the acceptability indicates that the larger the amount of damage to the company, the less acceptable the behavior, and, consequently, it is less likely that the client will replicate it. Although the acceptability was not a justification, it seems that a more acceptable behavior is easier to justify. Therefore, the evidence that the acceptability mediates the influence of the amount of damage on the domino effect supports the idea that the lower the damage to the company, the more justifiable the behavior, and, consequently, the more likely it is to be replicated.

Additionally, the level of ethics modifies how the amount of damage influences the acceptability, supporting $\mathrm{H}_{3}$. Specifically, for subjects with higher levels of ethics, the effect of the amount of damage on the acceptability of the DCB is negative, indicating that for these subjects, ethics reduces the acceptability of the DCB with the amount of damage increase more than for subjects with lower levels of ethics. 
Finally, we showed that the level of perceived risk and the social link influences the relationship between the amount of damage and the domino effect. This finding supports $\mathrm{H}_{4}$ and H6. When the subject perceives a high risk or when there is more probability of discovering and punishing the behavior, the customer reduces his intention to replicate a DCB in the high amount of damage condition. However, it is interesting that the perceived risk does not influence the domino effect in the low amount of damage condition. This result should be explored in future studies, as it is possible that in the low amount of damage condition, the domino effect can be easily justifiable, compared to a high amount of damage, in which the advantage taken by the client is clearer. In the same way, when the person is a group insider, the social link reduces the likelihood of replicating the DCB, supporting the hypotheses that the social proximity acts as an informal control mechanism to prevent an imbalance in the group.

\section{REFERENCES}

Albers-Miller, N. D. (1999). Consumer misbehavior: Why people buy illicit goods. Journal of Consumer Marketing, 16, 273-287. doi: doi/10.1108/07363769910271504

Akers, R. L., \& Sellers, C. S. (2004). Criminological theory: Introduction and evolution, 2nd ed. Chicago: Routledge.

Babcock, L., \& Loewenstein, G. (1997). Explaining bargaining impasse: The role of self-serving biases. Journal of Economic perspectives, 11(1), 109-126. doi: 10.1257/jep.11.1.109

Baker, M. A., Magnini, V. P., \& Perdue, R. R. (2012). Opportunistic customer complaining: Causes, consequences, and managerial alternatives. International Journal of Hospitality Management, 31, 295-303. doi: 10.1016/j.ijhm.2011.06.004

Bandura, A. (1963). The role of imitation in personality development. Journal of Nursery Education, 18(3), 1-9.

Bandura, A. (1977). Self-efficacy: Toward a unifying theory of behavioral change. Psychological Review, 84, 191-215. doi: 10.1016/01466402(78)90002-4

Blais, A. R., \& Weber, E. U. (2006). A domain-specific risk-taking (DOSPERT) scale for adult populations. Judgement and Decision Making, 1, 33-47.

Daunt, K. L., \& Greer, D. A. (2015). Unpacking the perceived opportunity to misbehave: The influence of spatio-temporal and social dimensions on consumer misbehavior. European Journal of Marketing, 49, 15051526. doi: 10.1108/EJM-01-2014-0061

Daunt, K. L., \& Harris, L. C. (2011). Customers acting badly: Evidence from the hospitality industry. Journal of Business Research, 64, 10341042. doi: 10.1016/j.jbusres.2010.10.010

Dootson, P., Neale, L., \& Fullerton, S. (2014). When size matters: Exploring perceptions and justifications of deviant consumer behavior. Advances in Consumer Research, 42, 298-301.
Ferrell, O. C., \& Gresham, L. G. (1985). Framework for contingency ethical decision understanding making in marketing. Journal of Marketing, 49, 87-96. doi: $10.1177 / 002224298504900308$

Fisk, R., Grove, S., Harris, L. C., Keeffe, D. A., Daunt, K. L., Russell-Bennett, R., \& Wirtz, J. (2010). Customers behaving badly: A state of the art review, research agenda and implications for practitioners. Journal of Services Marketing, 24, 417-429. doi: 10.1108/08876041011072537

Fullerton, R. A., \& Punj, G. (1993). Choosing to misbehave: A structural model of aberrant consumer behavior. Advances in Consumer Research, 20, 570-574.

Fullerton, S., Kerch, K. B., \& Dodge, H. R. (1996). Consumer ethics: An assessment of individual behavior in the market place. Journal of Business Ethics, 15, 805-814. doi: 10.1007/BFo0381744

Gino, F., Ayal, S., \& Ariely, D. (2009). Contagion and differentiation in unethical behavior: The effect of one bad apple on the barrel. Psychological Science, 20(3), 393-398. doi: 10.1111/j.14679280.2009.02306.x

Gino, F., Gu, J., \& Zhong, C. (2009). Contagion or restitution? When bad apples can motivate ethical behavior. Journal of Experimental Social Psychology, 45, 1299-1302.

Harris, L., \& Reynolds, K. L. (2003). The consequences of dysfunctional customer behavior. Journal of Service Research, 6, 144-161. doi: $10.1177 / 1094670503257044$

Hayes, A. F. (2013). Introduction to mediation, moderation, and conditional process analysis: A regression-based approach. New York and London: Guilford Press.

Kowalski, R. M. (1996). Complaints and complaining: Functions, antecedents, and consequences. Psychological Bulletin, 119, 179196. doi: 10.1037/0033-2909.119.2.179

Libai, B., Bolton, R., Bügel, M. S., Ruyter, K. Götz, O., Risselada, H., \& Stephen, A. T. (2010). Customer-to-customer interactions: Broadening the scope of word of mouth research. Journal of Service Research, 13, 267-282. doi: 10.1177/1094670510375600

Liao, S., Chou, C. Y., \& Lin, T. H. (2015). Adverse behavioral and relational consequences of service innovation failure. Journal of Business Research, 68(4), 834-839. doi: 10.1016/j.jbusres.2014.11.037

Mazar, N., Amir, O., \& Ariely, D. (2008a). The dishonesty of honest people: The theory of self-concept maintenance. Journal of Marketing Research, 45(6), 633-644. doi: 10.1509/jmkr.45.6.633

Mazar, N., Amir, O., \& Ariely, D. (2008b). More ways to cheat-expanding the scope of dishonesty. Journal of Marketing Research, 45(6), 651653. doi: 2010-01163-004

Miyazaki, A. D. (2009). Perceived ethicality of insurance claim fraud: Do higher deductibles lead to lower ethical standards? Journal of Business Ethics, 87, 589-598. doi: 10.1007/s10551-008-9960-4

Morsello, M. F. (2004). Responsabilidade civil no transporte aéreo. São Paulo: Universidade de São Paulo.

Muncy, J., \& Vitell, S. J. (2005). The Muncy-Vitell consumer ethics scale: A modification and application. Journal of Business Ethics, 62, 267275. doi: 10.1007/s10551-005-7058-9

Neale, L., \& Fullerton, S. (2010). The international search for ethics norms: Which consumer behaviors do consumers consider (un) acceptable? Journal of Services Marketing, 24(6), 476-486. doi: $10.1108 / 08876041011072591$ 
Sampson, R. J., Morenoff, J. D., \& Gannon-Rowley, T. (2002). Assessing "neighborhood effects": Social processes and new directions in research. Annual Review of Sociology, 28(1), 443-478. doi: 10.1146/ annurev.soc.28.110601.141114

Schaefers, T., Wittkowski, K., Benoit, S., \& Ferraro, R. (2016). Contagious effects of customer misbehavior in access-based services. Journal of Service Research, 19, 3-21. doi: 10.1177/1094670515595047

Tajfel, H. (1982). Social psychology of intergroup relations. Annual Review of Psychology, 33(1), 1-39.

Wilkes, R. E. (1978). Fraudulent behavior by consumers. Journal of Marketing, 42, 67-75. doi: 10.1177/002224297804200410
Wirtz, J., \& Kum, D. (2004). Consumer cheating on service guarantees. Journal of the Academy of Marketing Science, 32(2), 159-175. doi: $10.1177 / 0092070303261416$

Wirtz, J., \& McColl-Kennedy, J. R. (2010). Opportunistic customer claiming during service recovery. Journal of the Academy of Marketing Science, 38(5), 654-675. doi: 10.1007/S11747-009-0177-6

Wu, C. H. J. (2007). The impact of customer-to-customer interaction and customer homogeneity on customer satisfaction in tourism servicethe service encounter prospective. Tourism Management, 28(6), 1518-1528. doi: 10.1016/j.tourman.2007.02.002

Wu, C. H. J. (2008). The influence of customer-to-customer interactions and role typology on customer reaction. The Service Industries Journal, 28(10), 1501-1513. doi: 10.1080/02642060802250310

\section{AUTHORS' CONTRIBUTIONS}

Denise Telli and Lélis Bales_trin Espartel worked on the conceptualization and theoretical-methodological approach. The theoretical review was conducted by Denise Telli and Clecio Falcao Araujo. Data collection was coordinated by Denise Telli and Clecio Falcao Araujo. Data analysis included Denise Telli, Clecio Falcao Araujo and Kenny Basso. All authors worked together in the writing and final revision of the manuscript. 